\title{
Joining of galvanized steel sheets and aluminum by REW technology using AlSi5 joining elements
}

\author{
P. Sejč*, Z. Gábrišová, B. Vanko, A. Schrek \\ Institute of Technologies and Materials, Faculty of Mechanical Engineering, Slovak University of Technology, \\ Pionierska 15, 83102 Bratislava, Slovak Republic
}

Received 9 January 2019, received in revised form 30 May 2019, accepted 31 May 2019

\begin{abstract}
In the present work, innovative resistance element welding (REW) technology is introduced for the joining of galvanized steel sheets to aluminum. The essence of the innovation was the use of an $\mathrm{Al}$ alloy joining element, which is suitable filler metal for brazing galvanized steel sheets and arc welding aluminum alloys.

Analysis of the joint structure shows that the use of suitable resistance heating parameters (current, time, force) results in a brazed joint between the face of the joining element and the steel sheet, and a welded joint between the joining element and the aluminum sheet. The strength of the obtained joints is equal to that of the joining element made of AlSi5 aluminum alloy.
\end{abstract}

K e y w o r d s: resistance element welding, steel/aluminum joints, joining element, properties, structure

\section{Introduction}

Nowadays, besides traditional welding technologies used in the joining of thin steel and non-ferrous metal sheets, such as MIG welding/brazing, resistance spot welding (RSW), and welding/brazing by laser beam [1-3], new welding/brazing and mechanical fastening methods are being used $[4,5]$.

The resistance element welding (REW) process can be characterized as a joining of sheets using a joining element (pin) and resistance heating. The technology was developed from conventional RSW and combined thermal and mechanical joining principles (Fig. 1) [6].

REW technology is most commonly used in the manufacture of lap joints of thin sheets [6-8]. Before welding, an opening is made in the upper material into which is inserted a joining element with a shank suitable for insertion into the opening and a head of a larger diameter (Fig. 1). One electrode of the RSW gun presses the joining element at the joint, the other acts on the bottom side of the joined sheet. The pressure and the electric current are applied simultaneously. The heat generated by the electrical resistance causes the materials to melt at the point of contact

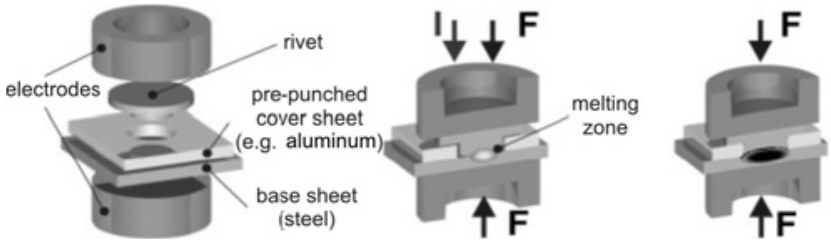

Fig. 1. The principle of welding by REW technology [6].

of the joining element with the base material (lower sheet), and a welding nugget is formed. Increasing the welding force ensures deformation of the joining element in the axial direction and hence a strong joint between the joining element and the upper material. In this way, a mechanical joint is made between the shank or the head of the joining element and the upper material [6]. In principle, this involves the creation of a fusion joint between the lower material and the joining element in combination with a positive fit and a force fit between the joining element and the upper material (Fig. 2).

In general, this method has been developed to join steel materials to aluminum using a steel joining element. In this case, a welded joint is formed between

*Corresponding author: e-mail address: pavol.sejc@stuba.sk 


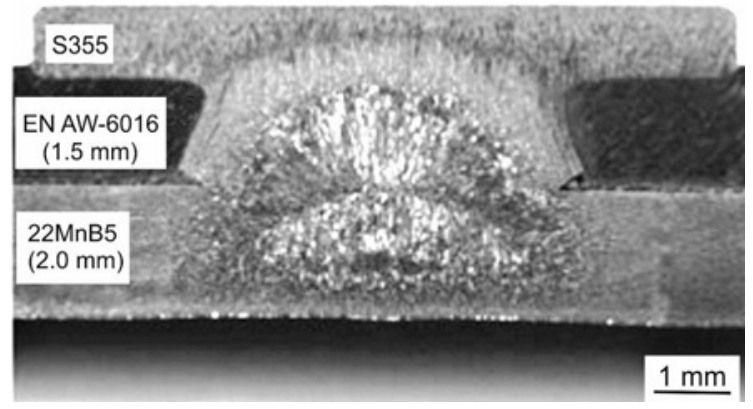

Fig. 2. The cross-section of the REW joint between the steel sheet and $\mathrm{Al}$ alloy sheet [6].

the steel sheet and joining element.

The main process parameters of REW are:

- welding current,

- welding time,

- clamping force.

The welding time is defined as the time during which the welding current flows through the welded materials. The welding time must be long enough to cause the joining element to melt but be as short as possible to avoid the excessive thermal influence of the heat affected zone (HAZ).

The clamping force significantly influences the thermal phenomena during the welding process by affecting the transition resistance between the materials and ensuring that the welded materials are assembled and remain in contact. Unlike conventional RSW, the clamping force also ensures deformation of the joining element in the axial direction. If the clamping force is sufficiently high, a strong force fit is formed between the joining element and the upper material due to deformations.

From the Joule-Lenz law [9]:

$$
Q=R I^{2} t,
$$

where $Q(\mathrm{~J})$ is the heat, $R(\Omega)$ is the electrical resistance, $I(\mathrm{~A})$ is the electric current, and $t(\mathrm{~s})$ is the current flow time. It is clear that the heat generated in the weld is directly proportional to the square of the welding current. In terms of thermal phenomena, the current density indicating the amount of welding current per unit area is also important. In this respect, the electrode contact surface with welded material is of great importance. Compared to RSW, the contact surface in REW not only depends on the geometric parameters of the electrodes but also on the geometry of the joining element.

\subsection{REW steel-aluminum bonding using an aluminum-based joining element}

In the standard technology of joining steel to aluminum by REW, the joining element is made of steel.
Between the joining element and the steel sheet, a fusion-welded joint is formed in the shape of the nugget (Fig. 2). The volume of the nugget material is heated during the welding process above the liquidus temperature of the joined materials (for unalloyed low carbon steel above $1540^{\circ} \mathrm{C}$ ), with a substantial portion of the heat being transferred to the aluminum sheet, and via the joining element and the steel sheet, to the water-cooled electrodes. When joining thin galvanized steel sheets (up to a thickness of $1 \mathrm{~mm}$ ), overheating of the joined material can lead to excessive destruction of the $\mathrm{Zn}$ coating on the electrode contact side, as well as an undesirable range of heat-induced stresses and deformations of the sheet. The extent of such deformations may be unacceptable, for example in the production of so-called "visible joints" on a car body. Besides, the low zinc melting temperature $\left(419^{\circ} \mathrm{C}\right)$ and its evaporation $\left(907^{\circ} \mathrm{C}\right)$ significantly reduce the life of the contact surfaces of the electrodes, which is a serious problem in RSW of galvanized steel sheets [9-11].

Under these conditions, a mechanical joint is created between the steel joining element and the aluminum sheet. The properties of the mechanical joint depend significantly on the correct choice of shape and geometry of the joining element and the opening in the sheet. The strength of the clamping of the aluminum sheet between the joining element and the steel sheet is proportional to the plastic deformation of the joining element (the essential role here is played by the clamping force during the resistance heating) and the coefficient of thermal expansion of the material of the joining element.

The overall strength of the joint depends to a large extent on the mechanical properties of the material of the joining element in the cast state (weld metal) or in the annealed state (Heat Affected Zone - HAZ). Both the steel sheet and the joining element are subject to strict requirements in terms of weldability: susceptibility to the formation of solidification and hydrogeninduced cracking. Recent methods of ultrasonic testing by TOFD and Phased Array [12] can be used to identify defects in welded joints.

In the proposed solution, the joining element, unlike the original REW technology, is made of a material that is suitable for brazing the lower sheet. Thus, the joint between the face of the joining element and the steel sheet does not result from mechanisms of fusion welding but brazing. Thus, the material selection does not have to meet the strict criteria for the filler metal, but it is necessary that under resistance heating conditions, a certain volume of the joining element is melted. After heating the joined sheet to the brazing temperature, the lower material is wetted by the molten metal of the joining element. With a suitable choice of joining element material and heating parameters, a brazed joint is produced without the use of flux or shielding gas. 
Table 1. Chemical composition of HX 220 BD - 100 MBO steel (wt.\%) [13]

\begin{tabular}{ccccccccc}
\hline $\mathrm{C}$ & $\mathrm{Ti}$ & $\mathrm{Si}$ & $\mathrm{Mn}$ & $\mathrm{P}$ & $\mathrm{S}$ & $\mathrm{Nb}$ & $\mathrm{Al}$ \\
\hline 0.1 & 0.12 & 0.5 & 0.7 & 0.08 & 0.025 & 0.09 & 0.10 \\
\hline
\end{tabular}

Ta ble 2. Chemical composition of aluminum alloy EN AW 1050A (wt.\%) [14]

\begin{tabular}{cccccccc}
\hline $\mathrm{Al}$ & $\mathrm{Si}$ & $\mathrm{Fe}$ & $\mathrm{Cu}$ & $\mathrm{Mn}$ & $\mathrm{Mg}$ & $\mathrm{Zn}$ & $\mathrm{Ti}$ \\
\hline 99.5 & 0.25 & 0.40 & 0.05 & 0.01 & 0.05 & 0.07 & 0.05 \\
\hline
\end{tabular}

Table 3. Chemical composition of EN AW - AlSi5 (wt.\%) [15]

\begin{tabular}{cccccccc}
\hline $\mathrm{Al}$ & $\mathrm{Si}$ & $\mathrm{Fe}$ & $\mathrm{Cu}$ & $\mathrm{Mn}$ & $\mathrm{Zn}$ & $\mathrm{Ti}$ & $\mathrm{Be}$ \\
\hline residue & $4.5-6.0$ & $\leq 0.6$ & $\leq 0.3$ & $\leq 0.05$ & $\leq 0.1$ & $\leq 0.15$ & $\leq 0.0003$ \\
\hline
\end{tabular}

Ta ble 4. Selected mechanical properties of experimental materials $[13,14,15]$

\begin{tabular}{lccc}
\hline Material & HX220BD $+\mathrm{Z}$ & EN AW1050A & EN AW AlSi5 \\
\hline Yield Strength, $R_{\mathrm{P} 0.2}(\mathrm{MPa})$ & $220-280$ & $75-85$ & $20-40$ \\
Tensile Strength, $R_{\mathrm{m}}(\mathrm{MPa})$ & $320-400$ & $105-145$ & $120-165$ \\
Elongation, $A_{80}\left(* A_{50}\right)(\%)$ & 32 & $* 20$ & $* 3-18$ \\
\hline
\end{tabular}

This new technical solution for joining galvanized steel sheet to aluminum alloy sheet was tested.

\section{Experimental part}

To produce the test samples, three different materials were used. The steel material was a sheet of $\mathrm{HX}$ 220 BD-100 MBO type (quality EN 10346/09) with a thickness of $0.8 \mathrm{~mm}$ galvanized on both sides. The thickness of the zinc coating was $15 \mu \mathrm{m}$. The chemical composition and selected mechanical properties of this steel are shown in Table 1 and Table 4. This steel is designed for cold forming, and it is characterized by low carbon content and a ferritic structure [13].

The steel sheet was joined to a sheet of technically pure aluminum EN AW-1050A (DIN Al99.5, STN 424005) with a thickness of $0.8 \mathrm{~mm}$ by using the joining element. The chemical composition and selected mechanical properties of the aluminum sheet are shown in Table 2 and Table 4.

The joining element was made by solid cold forming (pressing) from a material primarily used as filler metal in the form of wire for welding aluminum alloys by tungsten inert gas welding (TIG) [16]. It is an aluminum alloy of EN AW-AlSi5 type (EN AW4043, DIN 3.2245, EN ISO 18273: S Al 4043 (AlSi5)). The diameter of the wire used for producing the joining element was $4 \mathrm{~mm}$. The chemical composition and

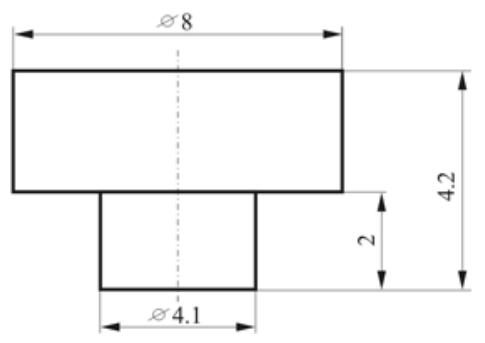

Fig. 3. Geometry and dimensions of the joining element.

selected mechanical properties are shown in Table 3 and Table 4 . The melting range of the material used is from 573 to $625^{\circ} \mathrm{C}$ [15]. The geometry and dimensions of the joining element used are shown in Fig. 3.

The structure of the joint using an aluminumbased joining element is greatly influenced by the properties of aluminum. Aluminum and its alloys are characterized by a relatively low melting temperature, substantially lower than that of steel material. This temperature ranges from 463 to $671^{\circ} \mathrm{C}$. The low melting point joining element preferably melts during heating, which is also supported by the high thermal conductivity of aluminum. With suitable heating parameters, the galvanized steel material does not melt but only heats up to the brazing temperature - the molten material of the joining element fulfills the function of 


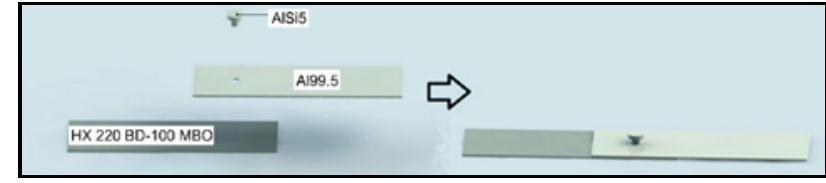

Fig. 4. Arrangement of welded materials.

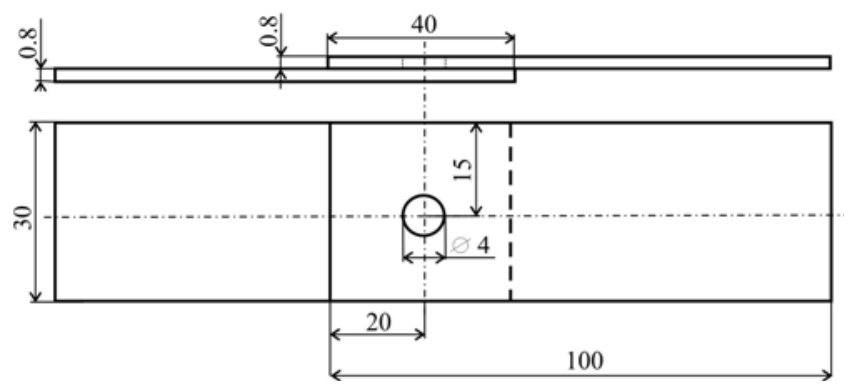

Fig. 5. Dimensions and position of joined sheets.

the braze filler metal. The base material (galvanized steel sheet) can be wetted with a suitable choice of the chemical composition of the joining element. An AlSi5 alloy, which is used as filler metal for the arc brazing of steel-aluminum joints [17], is suitable for this purpose. Brazing takes place in an inert protective atmosphere, Si taking over the deoxidizing function of the flux.

The joined sheets were overlapped, the lower sheet being steel and the upper aluminum. The aluminum sheet had a pre-fabricated hole in which the joining element was inserted. This arrangement and the test sample are shown in Figs. 4, 5.

The ARO type XMA $26 \mathrm{kVA}$ resistance welding gun with ULB 1.4 type universal VTS control system was used. The control system allows the control of the welding machine's output, the current flow time in the individual welding phases, as well as the clamping force. We produced 4 series of samples where the welding gun power output was changed by $10 \%$ in each series, which altered the value of the welding current. The actual welding parameters, such as current, voltage, time, and clamping force, were recorded by using the Miyachi measuring device of the Weld Checker MM-356 B type.

The type II electrodes ( $\mathrm{CuCrZr}$ ) used for RSW of galvanized steel sheets were used for joining purposes [9]. On the side of the joining element, the electrode had a flat contact surface, while on the side of the galvanized steel sheet, the electrode had a hemispherical contact surface.

The experiments aimed to optimize resistance heating parameters in REW of steel-aluminum joints with an AlSi5 joining element. The impact of the selected process parameters was evaluated by:

- the appearance of the joints and the occurrence

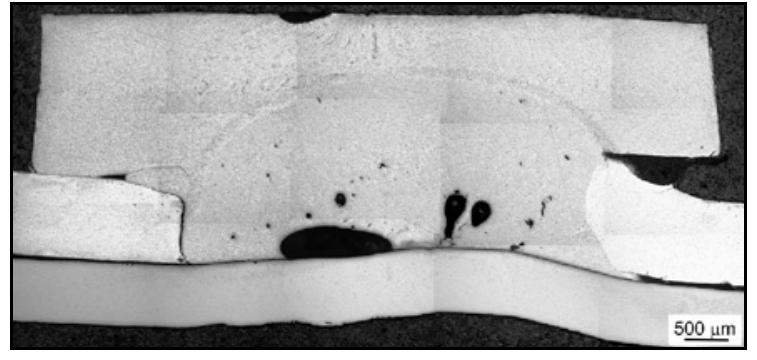

Fig. 6. Cross-section of sample no. 78.

of defects by visual control,

- the mechanical properties of the joints by a peel test and tensile test,

- the structure of the joints and internal defects by metallographic observation on cross-sections,

- the occurrence of fracture areas using the scan electron microscope (SEM) with EDS analyzer.

For a tensile test, we used the Instron 1195 universal testing machine.

\section{Results}

In the initial optimization of the parameters it was shown that the minimum heat input to form a strong joint is set at a minimum $60 \%$ of the power output of the welding machine on the control unit, the welding time of 12 periods, and the clamping force of $735 \mathrm{~N}$. These parameters became the basis for further testing of the REW process parameters in joining galvanized steel sheet with aluminum. The welding parameters used in the optimization process are presented in Table 5 .

\subsection{Evaluation of cross-sections of joints}

The joints showed the character of a welded/brazed joint (Figs. 6-9). On the side of the aluminum sheet, a welded joint was formed by mixing the molten metal sheet material and the joining element. A brazed joint was formed on the steel sheet side.

A cross-section of the sample welded at $60 \%$ of the welding gun power output $(I=8.7-8.9 \mathrm{kA}$, Table 5$)$ is shown in Fig. 6. The amount of heat transferred to the joint was the smallest in this sample. By heating, approximately $2 / 3$ of the height of the joining element was melted. Its deformation during joining was insufficient, i.e., the head of the joining element was not tight against the aluminum sheet. The melting of the aluminum sheet only occurred on the right side, and on the left side, there was no metallurgical joint between the joining element and the aluminum sheet. Even at the lowest heat input, porosity appeared in the structure. The porosity was mainly present at the interface 
Table 5. Optimization of welding parameters

\begin{tabular}{|c|c|c|c|c|c|c|}
\hline $\begin{array}{c}\text { Sample No. } \\
\text { No. }\end{array}$ & $\begin{array}{c}\text { Power output } \\
(\%)\end{array}$ & $\begin{array}{l}\text { Clamping force } \\
F(\mathrm{~N})\end{array}$ & $\begin{array}{c}\text { Welding current } \\
I(\mathrm{kA})\end{array}$ & $\begin{array}{l}\text { Voltage } \\
U(\mathrm{~V})\end{array}$ & $\begin{array}{l}\text { Welding time } \\
t \text { (per.) }\end{array}$ & $\begin{array}{l}\text { Heat input } \\
\quad Q(\mathrm{~kJ})\end{array}$ \\
\hline 72 & 60 & 735 & 8.78 & 1.10 & 12 & 2.32 \\
\hline 73 & 60 & 735 & 8.81 & 1.10 & 12 & 2.33 \\
\hline 74 & 60 & 735 & 8.70 & 1.12 & 12 & 2.34 \\
\hline 75 & 60 & 735 & 8.73 & 1.12 & 12 & 2.35 \\
\hline 76 & 60 & 735 & 8.90 & 1.10 & 12 & 2.35 \\
\hline 77 & 60 & 735 & 8.86 & 1.10 & 12 & 2.34 \\
\hline 78 & 60 & 735 & 8.84 & 1.08 & 12 & 2.29 \\
\hline 58 & 70 & 735 & 10.43 & 1.15 & 12 & 2.88 \\
\hline 59 & 70 & 735 & 10.48 & 1.14 & 12 & 2.87 \\
\hline 60 & 70 & 735 & 10.40 & 1.13 & 12 & 2.82 \\
\hline 61 & 70 & 735 & 10.38 & 1.15 & 12 & 2.86 \\
\hline 62 & 70 & 735 & 10.39 & 1.14 & 12 & 2.84 \\
\hline 63 & 70 & 735 & 10.37 & 1.15 & 12 & 2.86 \\
\hline 64 & 70 & 735 & 10.33 & 1.15 & 12 & 2.85 \\
\hline 51 & 80 & 735 & 11.77 & 1.21 & 12 & 3.42 \\
\hline 52 & 80 & 735 & 11.72 & 1.22 & 12 & 3.43 \\
\hline 53 & 80 & 735 & 11.81 & 1.20 & 12 & 3.40 \\
\hline 54 & 80 & 735 & 11.84 & 1.17 & 12 & 3.32 \\
\hline 55 & 80 & 735 & 11.76 & 1.20 & 12 & 3.39 \\
\hline 56 & 80 & 735 & 11.71 & 1.22 & 12 & 3.43 \\
\hline 57 & 80 & 735 & 11.78 & 1.20 & 12 & 3.39 \\
\hline 65 & 90 & 735 & 12.89 & 1.23 & 12 & 3.81 \\
\hline 66 & 90 & 735 & 12.93 & 1.24 & 12 & 3.85 \\
\hline 67 & 90 & 735 & 12.85 & 1.22 & 12 & 3.76 \\
\hline 68 & 90 & 735 & 12.77 & 1.27 & 12 & 3.84 \\
\hline 69 & 90 & 735 & 12.78 & 1.26 & 12 & 3.86 \\
\hline 70 & 90 & 735 & 12.90 & 1.22 & 12 & 3.78 \\
\hline 71 & 90 & 735 & 12.67 & 1.29 & 12 & 3.92 \\
\hline
\end{tabular}

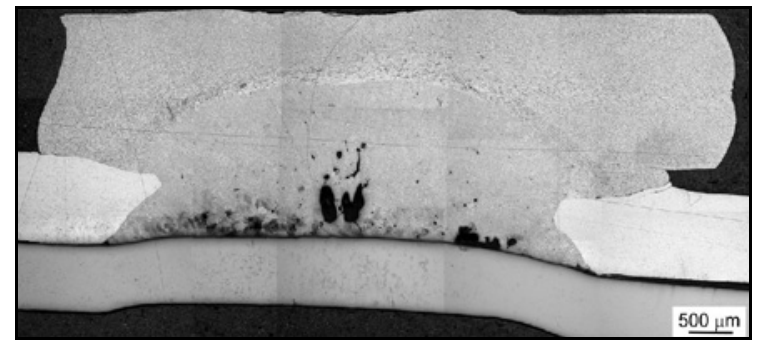

Fig. 7. Cross-section of sample no. 64 .

between the joining element and the steel sheet. The deformation of the steel sheet was minimal, without any changes in the sheet thickness.

In Fig. 7 is a cross-section of a sample that was made at $70 \%$ of the maximum welding gun power output ( $I=10.33-10.48 \mathrm{kA}$, Table 5$)$. Melting of the joining element was again about $2 / 3$ of its height. The porosity of the joint was less than when using $60 \%$ of the welding gun power output. The melted area was located at the center of the joining element. However, its head did not sit tightly to the right side of the aluminum sheet, which in some cases allowed the molten metal to spatter out of the weld area. Since the lower

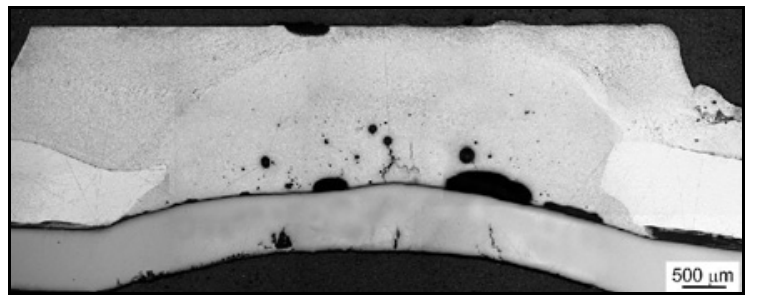

Fig. 8. Cross-section of sample no. 57.

electrode had a hemispherical shape, there was also a partial deformation of the steel sheet without changing the thickness.

The cross-section of the joint made at $80 \%$ of the maximum welding gun power output $(I=11.71-$ $11.84 \mathrm{kA}$, Table 5) is shown in Fig. 8. During the joining process, a relatively large volume of the joining element melted while the melting range in the middle reached almost the top of the head. Here also the cross-section of the sample showed some porosity. From the shape of the melted area, it is obvious that during the heating process, a welded joint was formed between the joining element and the aluminum sheet. 


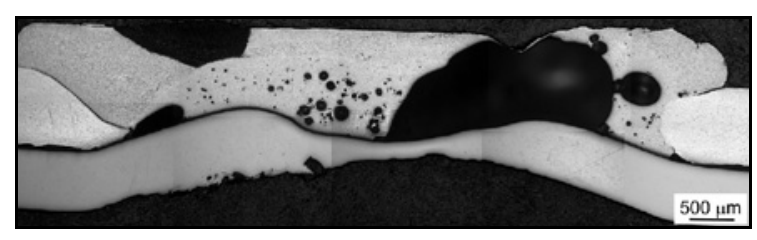

Fig. 9. Cross-section of sample no. 71.

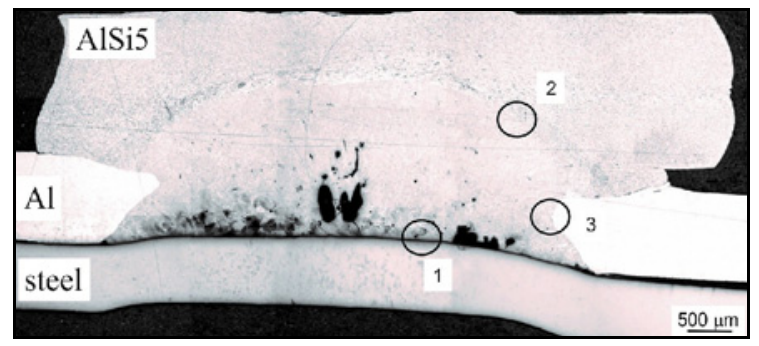

Fig. 10. A detailed view of the dissimilar joint: 1 - Interface between the joining element and the steel sheet; 2 - The fusion boundary of the joining element; 3 - Detail of the fusion zone of the aluminum sheet.

The right side of the figure shows the displacement of a certain volume of molten material under the head of the joining element. From the geometrical point of view, the melted area of the joining element is not in the middle, which could again be caused by small deviations in the positioning of the joined parts (sheets and joining element). Since the bottom electrode had a hemispherical shape, there was also a minor deformation of the steel sheet. There was no reduction in the thickness of the aluminum sheet outside of the joining element.

Increasing the welding gun power output to a maximum of $90 \%$ ( $I=12.67-12.93 \mathrm{kA}$, Table 5$)$ resulted in the deterioration of the joining element during the heating process. Figure 9 shows that in the case of excessive heat input, there was an enormous spatter of melted material, which caused significant shape changes (even destruction) of the joining element. The steel sheet was also significantly deformed, and a substantial reduction of its thickness was observed.

\subsection{Evaluation of structure on cross-sections of joints}

A detailed view of the dissimilar welded-brazed joint (sample no. 64, see Table 5) is shown in Fig. 10. During the joining process, a certain amount of material of the joining element and aluminum sheet was melted. The galvanized steel sheet remained solid during the joining process. It is further evident from the figure that the bottom steel sheet was well wetted by the molten braze metal of the joining element. This fact is also documented by the detail of the inter-

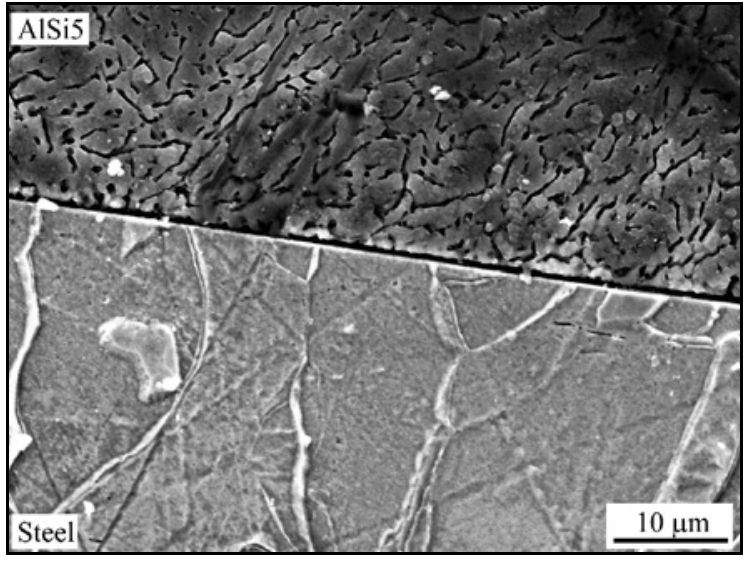

Fig. 11. The interface between the joining element and the steel sheet (SEM, etched in HF).

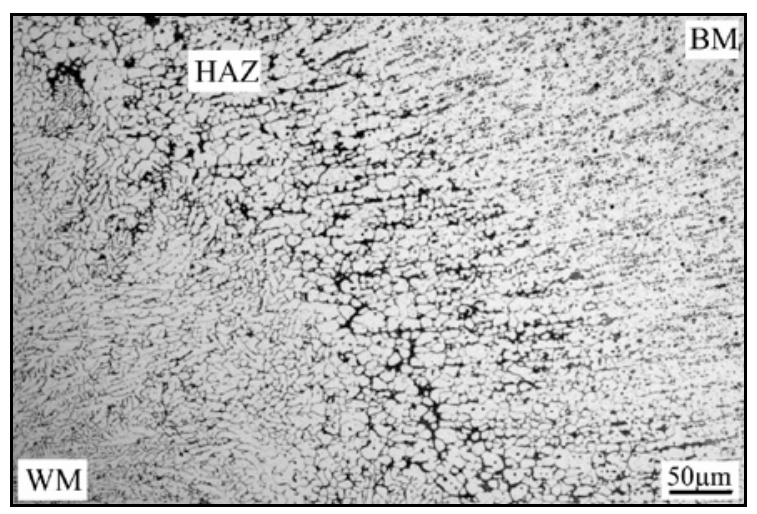

Fig. 12. The fusion boundary of the joining element (etched in $\mathrm{HF}$ ).

face between the joining element and the steel sheet (Fig. 11). Measuring showed that the interfacial intermetallic compounds (IMC) layer at the middle of the joint was about $1 \mu \mathrm{m}$ thick. The material on the side of the joining element had a characteristic cast structure, while in the steel sheet heated to the brazing temperature there was no significant grain coarsening.

The structure of the AlSi5 joining element consisted of a solid solution of $\alpha(\mathrm{Al})$ and the eutectic mixture of $\alpha(\mathrm{Al})+\beta(\mathrm{Si})$, see Fig. 12. Solid cold forming in the production of the joining element caused a characteristic deformation of the original grains.

The detail of the fusion boundary (Fig. 12) illustrates the cast structure of the material on the side of the weld metal, HAZ with coarse grain structure, and the base material (BM) without thermal influence on the preserved row structure.

A welded joint was formed between the joining element and the aluminum sheet. The detail of the fusion zone is in Fig. 13. The figure illustrates the extension of the $\alpha(\mathrm{Al})$ phase dendrites from the aluminum sheet 


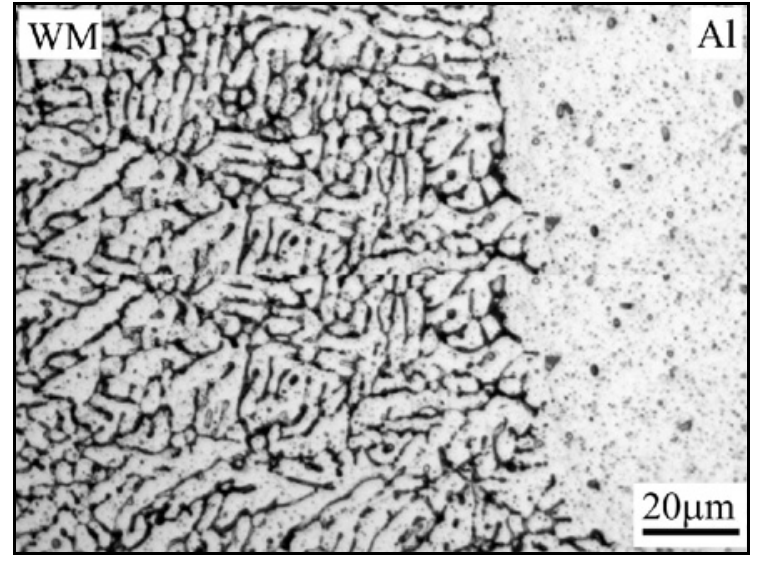

Fig. 13. Detail of the fusion zone of the aluminum sheet (etched in HF).

$$
\mid
$$

Fig. 14. Loading of the samples.

to the multi-phase cast structure of the melted joining element. The dark areas in the structure of the aluminum sheet result from the metallographic preparation of the cross-section of the joint.

\subsection{Evaluation of joint strength by the tensile test}

For the tensile test, we made 4 series of 5 samples with welding gun power outputs of $60,70,80$, and $90 \%$ (Table 5 ). The values obtained during the tensile test of joints made under different joining conditions were compared with the mechanical properties of the AlSi5 rod from which the joining elements were made (Table 4).

Because it was not possible to determine the initial cross-section area of the joint $\left(S_{0}\right)$, the maximum $F_{\max }$ load obtained during the tensile test was compared for the evaluation of the strength properties. The samples were loaded as shown in Fig. 14. As the joints were shear stressed (also partly bend stressed) during the test, we compared the mechanical properties of the joints and the material for manufacturing the joining element according to the following analysis.

If we only consider the shear stress at the static load on the butt/lap joints, we can calculate the shear stress $\tau(\mathrm{MPa})$ based on the relation below (2):

$$
\tau=\frac{F_{\mathrm{n}}}{\frac{\pi d^{2}}{4}} \leq \tau_{\mathrm{Dzv}}
$$

where $F_{\mathrm{n}}(\mathrm{N})$ is the normal load, $d(\mathrm{~mm})$ is the diameter of the weld nugget, and $\tau_{\mathrm{Dzv}}(\mathrm{MPa})$ is the allowable shear stress.

The allowable shear stress $\tau_{\text {Dzv }}(\mathrm{MPa})$ can be determined by the permitted tensile stress $\sigma_{\mathrm{D}}(\mathrm{MPa})$, as follows, Eq. (3):

$$
\tau_{\mathrm{Dzv}}=0.65 \sigma_{\mathrm{D}}
$$

where

$$
\sigma_{\mathrm{D}}=R_{\mathrm{m}}
$$

To compare the properties of the joining element with the properties of the joint, without considering the deformation of the joining element at the joining point, we can then use the Eq. (5):

$$
F_{\mathrm{n}} \leq 0.65 F_{\max }
$$

where $F_{\max }(\mathrm{N})$ is the maximum load determined by the tensile test of the joining element.

Since the average measured value of the maximum load in the tensile test of the material (rod), which the joining elements were made from, was $F_{\max }=2950 \mathrm{~N}$, then (Eq. (6)):

$$
F_{\mathrm{n}} \leq 1917.5,(\mathrm{~N})
$$

From the above analysis it is clear that, under the given conditions, the metallurgical joint is sufficiently strong, if the force required to break the sample exceeds the value of $1917.5 \mathrm{~N}$ in the shear stress test.

The effect of the energy applied to the joint (represented by the welding gun power output in \%) at the force required to break the sample is shown in Fig. 15.

It is clear from the graph that the highest $F_{\max }$ values were recorded at $80 \%$ of the welding gun power output (corresponding to a welding current of $I=$ 11.71 to $11.84 \mathrm{kA}$, Table 5$)$. At higher power output (90\%, I = 12.67-12.93kA, Table 5), the occurrence of errors (porosity, spatter) had a negative effect on the strength of the joint. The most consistent joint strength (represented by $F_{\max }$ ) approaching condition (6) was measured at $70 \%$ of the welding gun power output ( $I=10.33-10.48 \mathrm{kA}$, Table 5$)$, which is very important for the practical application of the used joining technology. 


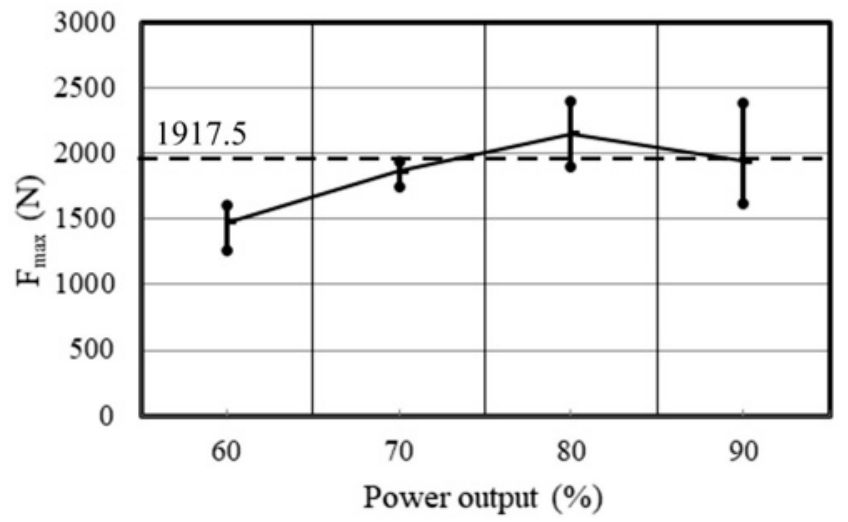

Fig. 15. The effect of welding gun power output on the $F_{\text {max }}$ load required to break the sample.
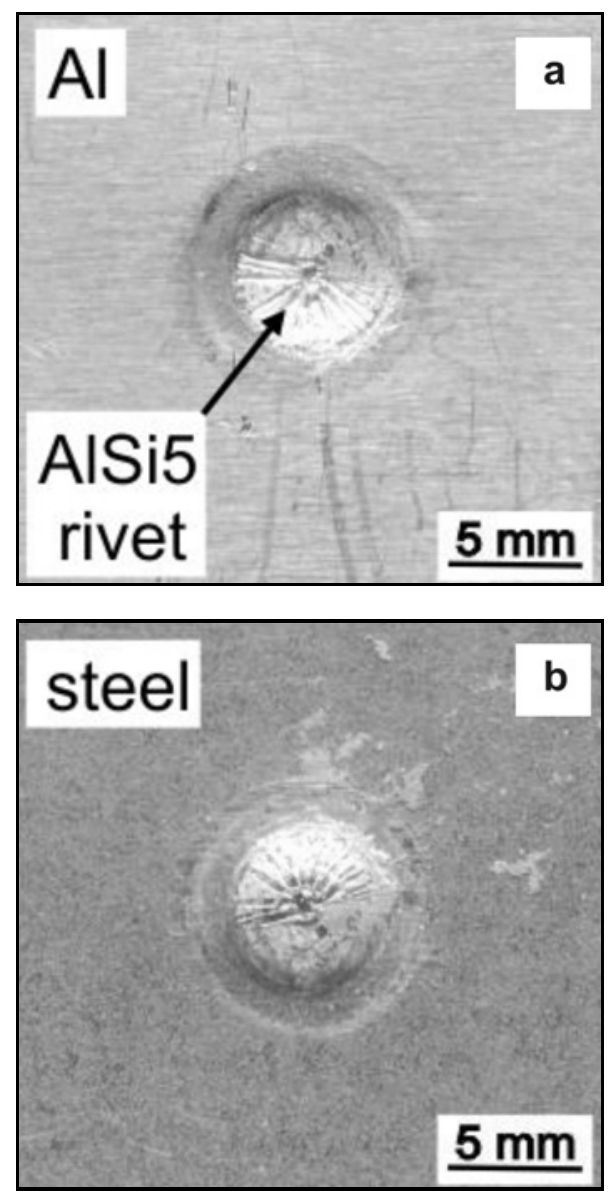

Fig. 16. Detailed view of samples no. 62 after a tensile test.

\subsection{Evaluation of the fracture area of joints}

In the tensile test, the integrity of the joint at the interface between the joining element and the galvanized steel sheet (Fig. 16) failed in all cases. At this point, the connection had the character of the brazed joint.

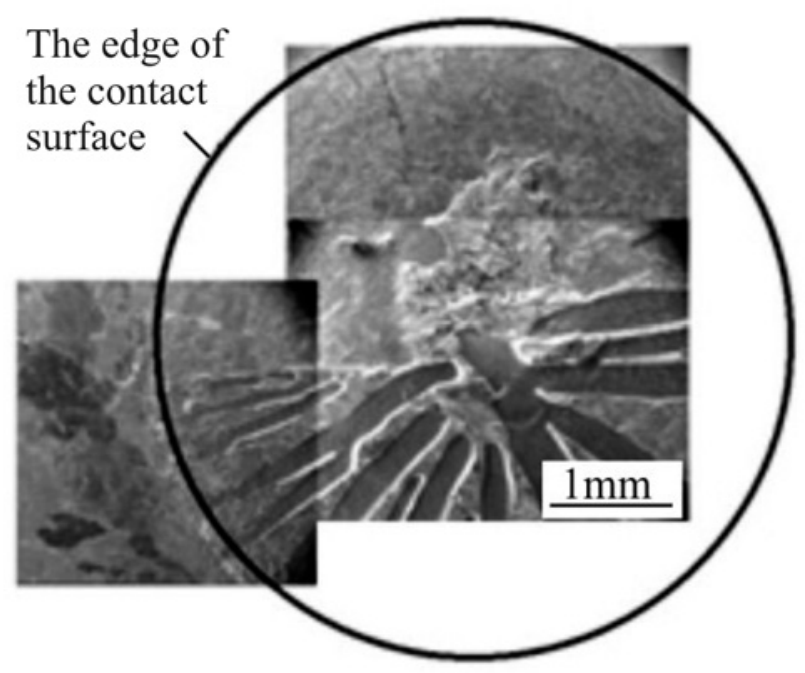

Fig. 17. SEM of the fracture surface on the side of the galvanized steel sheet.

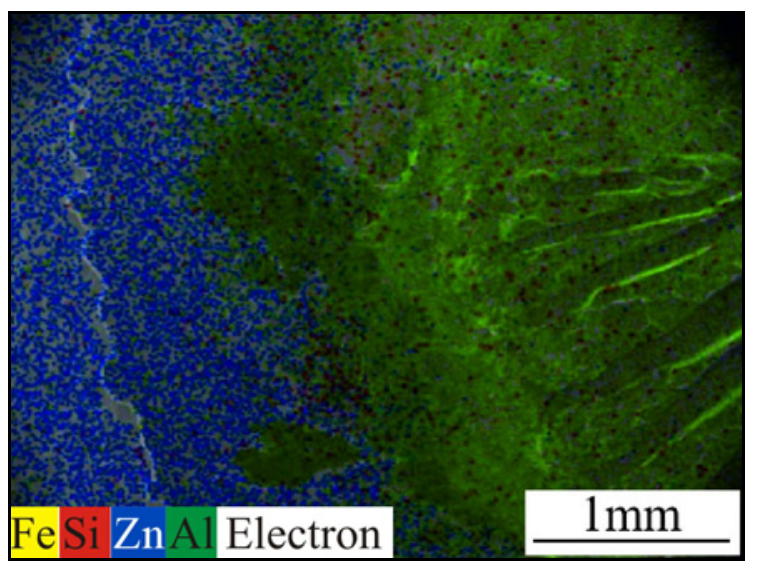

Fig. 18. SEM of the fracture surface on the side of the galvanized steel sheet.

The samples joined at $70 \%$ of the maximum welding gun power output were selected for the evaluation of the structure of the fracture area (Fig. 16). As shown in the figure, the surface of the steel sheet was well wetted by the molten metal of the joining element. The spatter of molten metal in the area between the sheets was minimal. Sporadic pores were identified in the joint.

The fracture surface detail on the steel sheet from the scanning electron microscope (SEM) is shown in Fig. 17. The contour line represents the edge of the contact surface between the joining element and the galvanized steel sheet. As illustrated by the maps of the elements, obtained from the left side of the edge part (Fig. 18), as well as from the central part of the contact surface (Fig. 19), a suitable condition for wetting the galvanized steel sheet with molten metal of 

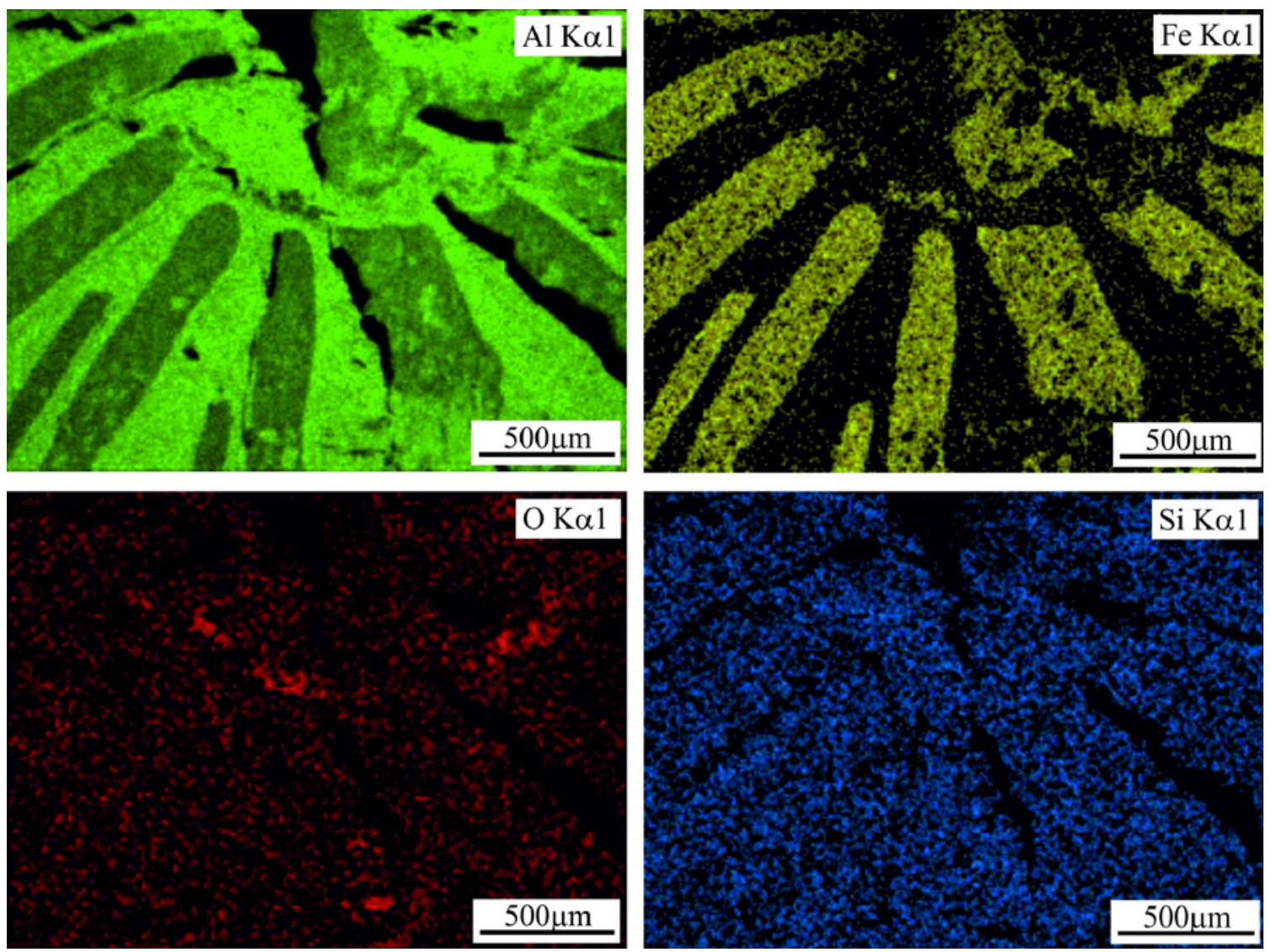

Fig. 19. Map of the elements in the central part of the contact surface.

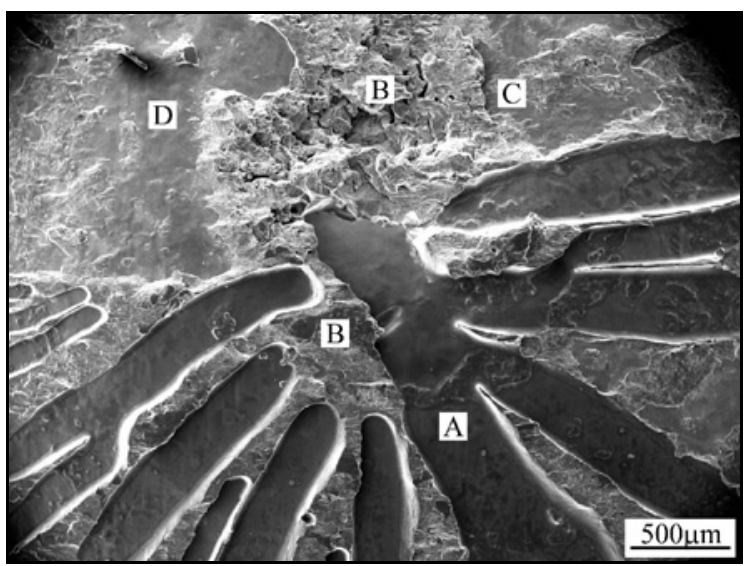

Fig. 20. Detail of the central part.

the joining element was created during the resistance heating process. The basic component of the joining element - aluminum - was identified in the central part (Fig. 19), as well as at the edges of the contact surface (Fig. 18). This ensured the primary conditions for a brazed joint. As shown in Fig. 18, the original zinc protective layer was identified on the steel sheet on the left edge of the contact surface, which is important in terms of maintaining the resistance of the

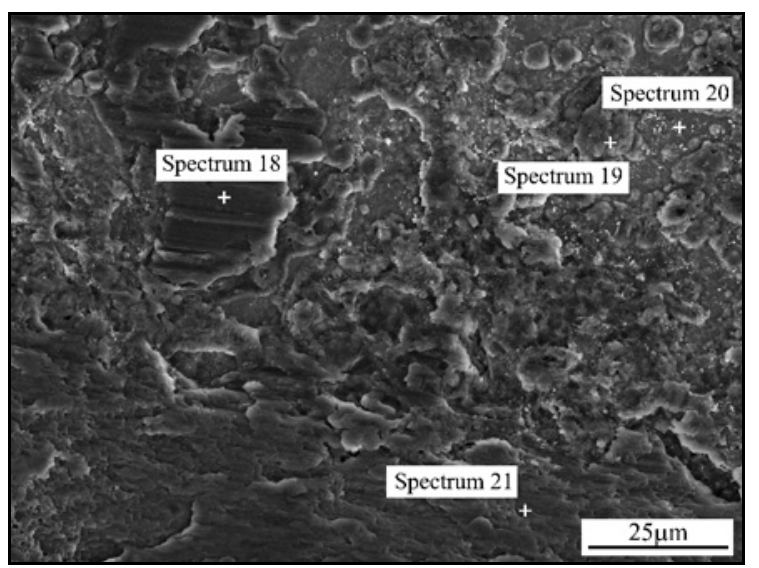

Fig. 21. Surface topography of area A of the contact surface.

material to atmospheric corrosion.

The detail of the central part of the fracture surface (Fig. 20) shows that the fracture area between the joining element and the galvanized steel sheet does not have a simple geometric shape. For the local shape and the character of the fracture, the entire contact surface can be divided into several zones:

A and D: The surface of the steel sheet wetted by molten metal of the joining element (AlSi5); 
Table 6. EDS analysis of selected A zone locations (see Fig. 21)

\begin{tabular}{crrrr}
\hline Elements (at.\%) & Spec. 18 & Spec. 19 & Spec. 20 & Spec. 21 \\
\hline $\mathrm{O}$ & 2.95 & 5.59 & 8.93 & 94.13 \\
$\mathrm{Al}$ & 92.53 & 89.06 & 28.23 & 3.12 \\
$\mathrm{Si}$ & 3.04 & 3.33 & 55.17 & 1.47 \\
$\mathrm{Fe}$ & 1.17 & 1.49 & 5.89 & 0 \\
$\mathrm{Zn}$ & 0.31 & 0.54 & & \\
\hline
\end{tabular}

Table 7. EDS analysis of selected B, C, D zone locations (see Fig. 22)

\begin{tabular}{ccccrr}
\hline Elements (in \%) & Spec. 9 & Spec. 10 & Spec. 11 & Spec. 12 & Spec. 13 \\
\hline $\mathrm{O}$ & 0 & 0 & 0 & 0 & 1.49 \\
$\mathrm{Al}$ & 81.00 & 11.70 & 81.98 & 80.22 & 95.21 \\
$\mathrm{Si}$ & 2.17 & 0.90 & 3.17 & 3.50 & 2.97 \\
$\mathrm{Fe}$ & 16.82 & 87.40 & 14.85 & 16.27 & 0.33 \\
\hline
\end{tabular}

Table 8. EDS analysis of selected B, C zone locations (see Fig. 24)

\begin{tabular}{ccccc}
\hline Elements (at.\%) & Spec. 5 & Spec. 6 & Spec. 7 & Spec. 8 \\
\hline $\mathrm{O}$ & 0.89 & 0 & 1.31 & 1.87 \\
$\mathrm{Al}$ & 97.79 & 99.11 & 95.11 & 96.89 \\
$\mathrm{Si}$ & 1.32 & 0.89 & 3.30 & 1.24 \\
$\mathrm{Fe}$ & 0 & 0 & 0.27 & 0 \\
\hline
\end{tabular}

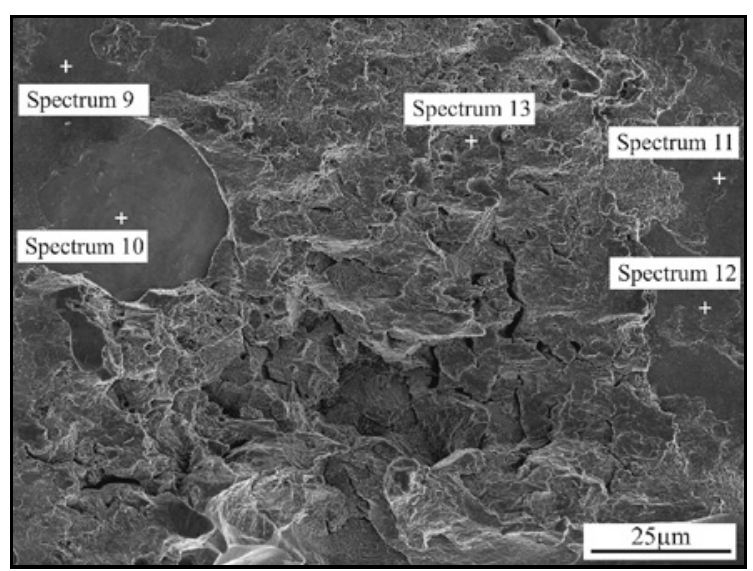

Fig. 22. Surface topography of areas B, C, D.

B: Fracture zone without significant tears and shrinkage porosity;

C: Fracture zone in the central part of the joint, characterized by occurrence of tears and shrinkage porosity.

The topography of zone A is shown in Fig. 21. The surface of the base material (galvanized steel sheet) was only wetted by the molten metal of the joining element in this area. There was no connection between the joining element and the steel sheet in zone A. EDS

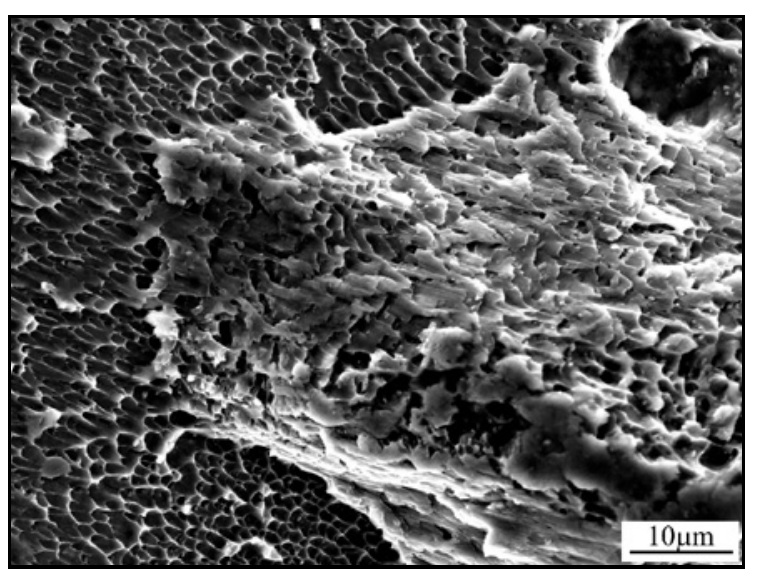

Fig. 23. Detail of zone B with a characteristic dimpled ductile fracture.

analysis of selected zones (Table 6 ) shows that the surface was predominantly a solid solution of $\alpha(\mathrm{Al}+\mathrm{Si})$ (Table 6, Spectra 18, 19, 21) with a single occurrence of phase $\alpha\left(\mathrm{Fe}_{2} \mathrm{Al}\right)$ (Table 6, Spectrum 20).

Figure 22 shows the fracture zone in the central part of the contact surface (zones B and C). As documented in Table 7, fracture occurred in zones where the structure was formed by a solid solution $\alpha(\mathrm{Al}+\mathrm{Si}$ ) (Table 7, Spectrum 13). The fracture zone mostly had a dimpled ductile appear- 


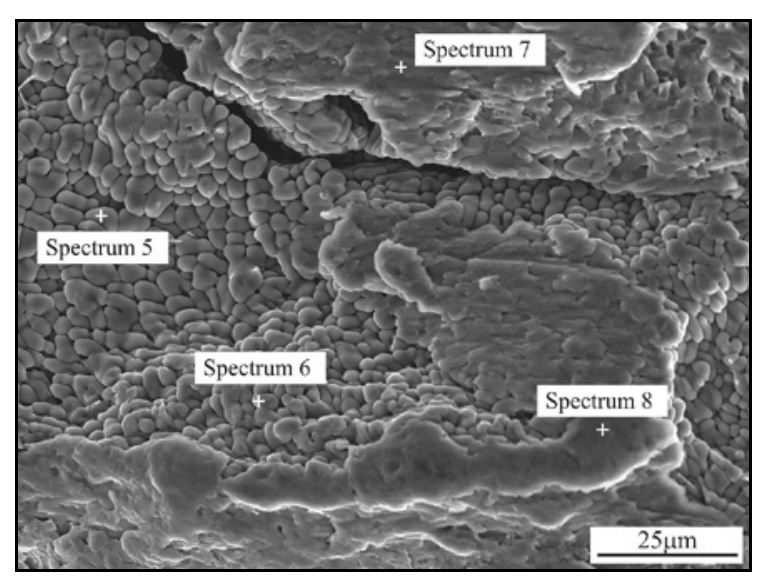

Fig. 24. Fracture surface.

ance with the occurrence of shear fracture areas (Fig. 23).

On the contact surface in zone $\mathrm{C}$, there were still areas with a typical dimpled structure topography, Fig. 24. EDX analysis on dendritic faces showed that they were made up of solid solutions of $\alpha(\mathrm{Al}+\mathrm{Si})$ (Table 8, Spectra 5, 6, 7, 8). It was also possible to observe shrinkage porosity and tears on the contact surface. This probably occurred during the solidification and cooling of the molten metal, Fig. 24.

At the boundary of zone $\mathrm{C}$ and in zone $\mathrm{D}$, where the galvanized steel sheet was only wetted by the molten metal of the joining element, were areas consisting of solid solution $\alpha(\mathrm{Fe})$ (Table 7, Spectrum 10), solid solution $\alpha(\mathrm{Al})$, phases $\mathrm{Fe}_{4} \mathrm{Al}_{13}$ or $\mathrm{FeAl}_{3}$, and phase $\tau_{5}(\alpha$-AlFeSi) (Table 7 , Spectra $9,11,12)$.

\section{Conclusions}

In the proposed solution, a modified method of producing lap joints of dissimilar materials by REW technology was introduced, whereby the joining element, unlike the original technology, was made of a material that is suitable for brazing the lower metal sheet. The specific objective of the experiments was to optimize the resistance heating parameters in the REW of the steel-aluminum dissimilar joints with an AlSi5 joining element in terms of selected mechanical properties. The following conclusions can be drawn from the results:

1. By optimizing the resistance heating parameters, suitable conditions were obtained to form a brazed joint between the joining element and the galvanized steel sheet (without the use of flux), and a weld joint between the joining element and the aluminum sheet. Only minor deformation of the steel sheet occurred in the production of the test samples with suitable parameters. The cause was the hemispherical shape of the contact surface of the electrode used. There was no change in the thickness of the aluminum sheet.

2. By increasing the heat input to the joint (an increase of the welding gun power output from 60 to $80 \%$ ), the volume of the melted material of the joining element gradually increased. The height to which the joining element melted changed from $2 / 3$ at its center to almost total melting at its center. When the welding gun power output was at $90 \%$ of the maximum, the materials at the joint were overheated above the critical state - the joining element was destroyed, large volumes of molten metal were spattered out, and the thickness of the steel sheet was significantly reduced.

3. During the tensile test, all samples fractured at the brazed joint. The lowest joint strength was noticed after using the lowest welding gun power output $(60 \%)$. Using $70 \%$, the average joint strength was close to the strength of the AlSi5 rod from which the joining elements were made. The maximum joint strength was measured using $80 \%$ of the welding gun power output. However, the increased dispersion of measured maximal load $F_{\max }$ values was noticed during the tensile test. Using $90 \%$ of the gun power output, we noticed a decrease in the strength of the joints produced by the highest heat input. This was influenced by the changes caused by overheating the joined materials, which resulted in increased spatter and porosity of joints.

4. The fracture surface between the joining element and the galvanized steel sheet had a relatively complicated geometrical shape. The integrity of the joints failed by a dimpled ductile fracture in areas, where the structure of the material consisted of a solid solution $\alpha(\mathrm{Al}+\mathrm{Si})$. On the contact surface, however, besides the zones of ductile fracture, there were also zones where only the galvanized sheet was wetted, and zones of exposed shrinkage porosity and tears that occurred during the fast solidification and cooling of the molten metal of the joining element. The analysis of the fracture surface between the aluminum alloy joining element and the galvanized steel sheet corresponds, from macro- and microstructural points of view, to the results published so far in works [18-20]. The thickness of the interfacial IMC layer between the AlSi5 joining element and the galvanized steel sheet with the occurrence of intermetallic compounds of the $\mathrm{Fe}_{x} \mathrm{Al}_{y}$ type was about $1 \mu \mathrm{m}$.

\section{Acknowledgements}

The results given in this paper were obtained as part of VEGA 1/0405/19 research project. Support of the UVP STU Bratislava ITMS 26240220084 project is also acknowledged. 


\section{References}

[1] Ünel, E., Taban, E.: Weld in the World, 61, 2017, p. 1. doi:10.1007/s40194-016-0386-9

[2] Mathieu, A., Pontevicci, S., Viala, J. C., Cicala, E., Matte, S., Grevey, D.: Materials Science and Engineering A, 435-436, 2006, p. 19. doi:10.1016/j.msea.2006.07.099

[3] Cui, L., Qiub, R., Hou, L., Shen, Z., Li, Q.: In: Proceedings of 5th International Conference on Advanced Design and Manufacturing Engineering, ICADME 2015, Amstelkade, Atlantis Press 2015, p. 777.

[4] Kang, J., Rao, H. M., Sigler, D. R., Carlson, B. E.: Procedia Structural Integrity, 5, 2017, p. 1425. doi:10.1016/j.prostr.2017.07.207

[5] Chen, J., Yuan, X., Hu, Z., Sun, Ch., Zhang, Y., Zhang, Y.: Materials Characterization, 120, 2016, p. 45. doi:10.1016/i.matchar.2016.08.015

[6] Meschut, G., Hahn, O., Janzen, V., Olfermann, T.: Weld in the World, 58, 2014, p. 65. doi:10.1007/s40194-013-0098-3

[7] Meschut, G., Janzen, V., Olfermann, T.: Journal of Materials Engineering and Performance, 23, 2014, p. 1515. doi:10.1007/s11665-014-0962-3

[8] Chastel, Y., Passemard, L.: Procedia Engineering, 81, 2014, p. 2104. doi:10.1016/j.proeng.2014.10.293

[9] Zhang, H., Senkara, J.: Resistance Welding: Fundamentals and Applications. 2nd Edition. Boca Raton, CRC Press 2017.
[10] Muftuoglu, F., Keskinel, T.: Turkish J. Eng. Env. Sci., 31, 2007, p.183.

[11] Hu, X., Zou, G., Dong, S. J., Lee, M. Y., Jung, J. P., Zhou, Y.: Materials Transactions, 51, 2010, p. 2236. doi:10.2320/matertrans.M2010239

[12] Dopjera, D., Koňár, R., Mičian, M.: Journal for Science, Research and Production, 14, 2014, p. 281.

[13] http://www.usske.sk/sk/produkty/ziarovopozinkovana-ocel/ocel-sbhefektom

[14] https://www.alumeco.com/aluminum/sheets/en-aw$1050 \mathrm{a} / 05-\mathrm{x}-/ \mathrm{p} / 390 / 3714$

[15] http://www.solyman.com/wp-content/uploads/ 2017/09/LNM-Al-Si5.pdf

[16] Blondeau, R. (Ed.): Metallurgy and Mechanics of Welding. Hoboken, Wiley 2008.

[17] Potesser, M., Schoeberl, T., Antrekowitsch, H., Bruckner, J.: In: Proceedings of EPD Congress 2006. Pittsburgh, The Minerals, Metals \& Materials Society 2006, p.167.

[18] Chen, N., Wanga, H. P., Carlson, B. E., Sigler, D. R., Wang, M.: Journal of Materials Processing Tech., 252, 2018, p. 348. doi:10.1016/j.jmatprotec.2017.09.035

[19] Wan, Z., Wang, H. P., Chen, N., Wang, M., Carlson, B. E.: Journal of Materials Processing Technology, 242, 2017, p. 12. doi:10.1016/j.jmatprotec.2016.11.017

[20] Qiu, R., Shi, H., Zhang, K., Tu, Y., Iwamoto, Ch., Satomaka, S.: Materials Characterization, 61, 2010, p. 684. doi:10.1016/i.matchar.2010.03.015 